\title{
Risk Assessment Model for Planning and Design Processes of Wastewater Treatment Plants
}

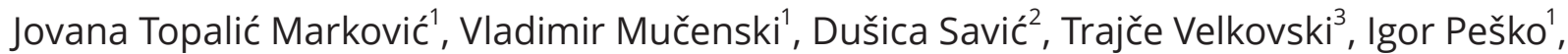 \\ Lidija Tomaš $^{4^{*}}$ \\ ${ }^{1}$ University of Novi Sad, Faculty of Technical Sciences, Department of Civil Engineering, 21102 Novi Sad, Republic of Serbia \\ ${ }^{2}$ Oil Industry of Serbia, 21102 Novi Sad, Republic of Serbia \\ ${ }^{3}$ University St. Cyril and Methodius, Faculty of Mechanical Engineering, 1000 Skopje, Republic of North Macedonia \\ ${ }^{4}$ City of Novi Sad, City Administration for Education, 21000 Novi Sad, Republic of Serbia \\ *Corresponding author, e-mail: lidija.tomas@uprava.novisad.rs
}

Received: 26 June 2020, Accepted: 22 September 2020, Published online: 22 October 2020

\begin{abstract}
Before joining the European Union, Serbia faces a big task related to the treatment and purification of wastewater. The capital of Serbia, Belgrade, and some larger cities do not have wastewater treatment plants. Although there are no plants in larger cities in Serbia, they still exist on the territory of the state itself. However, either they are not in good condition, or they do not work with the projected capacity or they do not work at all. This paper presents the model for risks quantification for the planning and design processes of wastewater treatment plants in which the risks are divided into 6 categories: legal, financial and economic, logistics, environmental protection, management and design risks. 37 risks have been defined, analyzed and evaluated by the experts participating in the Delphi method. Experts in various fields dealing with the planning, design or construction of wastewater treatment plants were selected to assess the risks through 2 rounds of Delphi methods and reach the consensus on major risks. By using statistical methods, it is determined that the experts reached the consensus after which each risk received its own relative weighting coefficient. Risk model has been initially verified by experts from Delphi team on two projects during construction phase. This model is important in the initial phases of the project, when the investor starts the project, as well as in the design phases.
\end{abstract}

\section{Keywords}

risk structure, quantification, Delphi method, wastewater treatment

\section{Introduction}

Every community produces both liquid and solid wastes as well as air emissions. The liquid waste (wastewater) is essentially the water supply of the community after it has been used in a variety of applications [1]. Hence, it is obvious that if there is no water - there is no settlement. If there is a settlement, there is wastewater. Wastewater is a constant and inseparable factor in human settlements [2]. The issue of protecting water from pollution is directly dependent on industrial and technological development, which results in the creation of legislative regulations in this area. Creation and implementation of laws for the protection of water from pollution has a significant impact on proper and efficient functioning of water protection [3]. It is clear that wastewater treatment is imperative for each country and each country, depending on the level of development, population and the amount of wastewater, has norms for wastewater treatment and the quality of the discharged water. Belgrade is the only capital city in Europe which does not have a wastewater treatment plant. However, Serbia awaits a big step ahead and this is the process of entering the European Union. There is a norm for wastewater treatment plants that every settlement with more than 2000 inhabitants has to oblige [3].

If we look back in time, wastewater engineering had been developing and as the population increased, the need for an engineered system for wastewater management in large cities became more evident [4]. Nowadays a lot of engineers are involved in the process of planning, designing and construction of wastewater treatment plants. The construction of a wastewater treatment plant is a complex and extensive project, which sometimes takes several years. Plants represent multi-million investments due to their complexity, equipment and a large number of people 
involved in all parts of the project. Risk analysis and risk management are important parts of the decision-making process in the construction industry. After analyzing different articles, guidelines and projects of wastewater treatment plants it can be concluded that the construction industry does not focus enough on project risk analysis and assessment in this area [5-7].

It is important that after doing the literature research, which includes review of journals, legal acts, books and also collecting information for existing plants, the main conclusion is that there is no unified methodology for identification and quantification of risks connected to civil engineering for wastewater treatment facilities. There are a lot of methods which explain the treatment processes and the quality of effluent [1,8-12] but those aspects are not the most important in terms of civil engineering.

Country-specific risk decisions are made by the company's top management, but they are separate from the technical, economic and operational risks of the project. Only certain participants in the project can see all the risks that arise in the life cycle of the project. Due to such occurrences on projects, there are various omissions and issues [5]. Basically, risk management is the process of identifying, approaching and prioritizing the risk followed by coordinated actions that should reduce, monitor and control the possibility and impact of adverse events. The goal of risk management is to reduce the possibility of uncertainties preventing the achievement of the project objectives [13].

\section{Case study}

The current situation in Serbia in the field of wastewater treatment is related to issues such as management and treatment of municipal and industrial wastewater, insufficient construction of sewer infrastructure in cities and industry, and especially insufficient construction of wastewater treatment plants. The need for large investments in the wastewater sector is also evident, while the low price of water is not enough to ensure the maintenance of the existing water supply and sewer systems, as well as to generate development and large investment cycles [14].

According to the data from 2015, Serbia belongs to the group of middle-developed countries in terms of municipal infrastructure. In [15], it is mentioned that $55 \%$ of the population in Serbia in 2015 had a sewer infrastructure, but less than $10 \%$ had a kind of wastewater treatment. Therefore, regarding the wastewater treatment infrastructure, this country takes almost the last place [15]. New data show that the trend of connection to the sewer network was constantly growing from 2000 to 2017 [16]. In 2017, $62.2 \%$ of the population of Serbia was connected to the sewer network. These data are disappointing. The current situation is bad with a tendency of deterioration [1].

Uncertainties and risks in the field of wastewater treatment are considered according to the design guidelines. Historically, the design itself is based on the requirements of the institutions, design standards accepted by the industry or legal regulations (industry standards tailored to specific requirements with individual amendments) [15]. The German ATV standard [17] and the instructions from the book Wastewater Treatment Disposal and Reuse [1] are most frequently used in Europe. In practice, risk factors in the design instructions $[1,12,17]$ are based on the improvement of the design that meets the requirements of the effluent (such as ammonia content, total nitrogen content...) but not the construction elements of the project. This risk model is different from the guidelines because it includes 37 risks strictly connected to the civil engineering aspects of projects. This model is important in the initial phases, as well as in the design phases when poor decisions can afterwards lead to poor efficiency and financial losses.

Research has shown that wastewater treatment plants are oversized and that tens of thousands of dollars would be saved using dynamic simulations and analyzing the risks with the highest risk factor [11]. In order for the purifiers to be built at an adequate location, in an adequate time interval, and to work with the designed capacity, it is necessary to consider the risks that each process brings. In this research, the authors focused on identification and assessment of the risks which are an integral part of the process of planning and designing wastewater treatment plants. The risks are organized into categories, and each of them individually can lead to delays in works and/or issues in exploitation, and thus directly affect economic and financial losses. When potential risks are identified and their solutions provided during the processes of planning and design, the project life cycle is more stable, i.e. with fewer disorders. Identification of the risks that may adversely affect the project, as well as their analysis and the analysis of the consequences for the project must be continued throughout the project and not only in the initial phases [18].

The consequences of the decisions made in the wastewater treatment process without consideration of socioeconomic and environmental parameters will be evident in time [19]. 


\section{Methodology}

The main goal of this research was to form a model of preliminary risk assessment of WWTP construction. Therefore, it was necessary to perform identification, analysis and evaluation, i.e. the assessment and evaluation of the risk significance of WWTP construction. The hypotheses put forward at the beginning of the research were: (1) It is possible to make a systematic, clear and applicable model of WWTP planning and design risk assessment and (2) It is possible to reach a risk assessment model using the Delphi method.

The research was conducted through several phases: research of literature and available data on WWTP, research of risk management methodology and risk structuring of WWTP construction, planning and implementation of the Delphi method by forming a questionnaire given to the experts (the participants in the Delphi method), the analysis and systematization of the obtained data and forming a model for preliminary risk assessment (with quantified risks).

\subsection{Risk structure for wastewater treatment plants}

The greatest responsibility for identifying risks, analyzing them and responding to them lies with the investor and their management team. Risk analysis provides the best results when performed at the very beginning of the project, although it is also important in other phases due to the disturbances that occur [20]. It is important to emphasize risk identification in the first phase of the project (choosing the investor, finance issues, location conditions, agreement with public utility companies, environmental organizations, etc.) as well as in the design phase. In this research, making of the risk structure started with making the concept for the risk management plan. The risk management plan is a list of rules or steps for risk management within the project. Due to that, potential risk factors were investigated. According to [21], risks can be divided into two categories. The first category - risks in the concept formation phase and the second - risks in the design phase. This was the starting point for forming a risk structure for the research. Construction risks i.e. the risks of construction projects are related to design, logistics, legal acts, environmental protection, management, finances, but also state policy [22]. For the past couple of years there has been an interest in risk management in the civil engineering industry. With risk identification, there is a formed base of risks, which is necessary for analysis and control. This can improve the knowledge about the issues in the civil engineering industry and the risks. If this analysis is well implemented, risk identification ensures successful management of the risk because an unknown risk becomes clear [6].

The risk structure formed for the purpose of this research had 37 risks divided into six groups (Table 2). Every group of risks was created on the basis of considering the issues on the project and the benefits of treating these risks at the beginning of the project. The first iteration was to send the risk structure to the group of experts who were qualified for the Delphi method. Each expert had to rate the risk with points from 1 to 5 (the Likert scale). Their decisions were based on the knowledge and experience in their professional work.

\subsection{The Delphi Method}

The Delphi method, i.e. the expert evaluation method, was used in order to obtain quantified risks. The Delphi method is the best known and most commonly used method of expert evaluation. The Delphi method or Delphi technique is a special type of research used in various scientific disciplines. It can be defined as a method that enables the process of group communication so that the process is effective and allows a group of individuals, as a whole, to agree on a solution to a complex problem, i.e. to reach a consensus [23].

The Delphi method is recognized as suitable for research, and it is, therefore, used in many studies and various scientific disciplines. In September 2008, a review of the Scopus database was conducted, and out of the 15.000 articles published by 4.000 publishers, 105 articles were based on the Delphi method [24]. The Delphi method is highly suitable for research precisely because the participants are anonymous and feel that they can freely provide their opinion.

When designing any research, the most important thing is to carefully select individuals for the team of participating experts. Depending on the method of research, one can clearly define a specific group of individuals who stand out in a certain field or choose participants who can help discover new ideas related to a certain field. This approach involves understanding a concept that is part of a much larger theory that the researcher plans to develop during the research [25].

According to the research by Ameyaw et al. [26], the project management and planning were processed in 29 out of 88 papers based on the Delphi method, where this method was used to obtain and evaluate the risk data. It is also important to note that between 3 and 93 experts 
participated in the research based on the Delphi method in the field of construction, and the number of rounds of research varied between 3 and 6. In [27], there is a description of the research engaging 14 experts: professors, engineers, contractors and experts in the field of international development. Their task was to assess 36 types of impact that might affect the safety of decentralized wastewater treatment plants. This research created the basis for further empirical research on topics related to wastewater treatment plants.

Relying on the conducted research, the research presented in this article was performed as a theoretical experiment where experts are situated in different geographical areas, more precisely in the territory of the states of Bosnia and Herzegovina as well as Serbia. Thirty-five experts with experience in planning, designing or constructing a wastewater treatment plant were selected to participate in the research. The team of 35 experts consisted of engineers of various professions, chemists and spatial planners from the Republic of Serbia and Bosnia and Herzegovina. The Delphi method was conducted in three rounds (zero, first and second round), the zero one of which represented the selection of experts based on their education and expertise influencing the research, whereas the remaining two involved risk analysis and assessment by the selected first round expert team.

The zero round involved the experts responding to the zero questionnaire with open and closed questions related to their experience and education. In order for an expert to declare themselves as an expert for the Delphi method, they need to meet 3 out of the 8 criteria shown and explained in Table 1. Thirty-three of them qualified as experts for the first round of research in which they assessed the risks.

Upon forming a team of experts consisting of 33 engineers after the zero round, the next step was giving a questionnaire to the experts. Each expert received a table with 37 risks (Table 2), with a detailed explanation of the risks and potential impact on the project. As it was said in this paper all risks are connected with civil engineering aspects of project not technology aspects. This model which is made with questions for every risk makes at the same time analyze of risk happening and how it will impact on project.

Every subquestion has score and in that score there is impact measured. That is not the standard method stated for impact. So for making of this model, experts had to rate the risks according to the Likert scale from 1 to 5 :
$1=$ negligible impact (the risk has a trivial impact on the project)

$2=$ low impact (the risk has low impact on the project)

$3=$ moderate impact (the risk has a medium impact on the project)

$4=$ large impact (the risk has a serious impact on the project)

$5=$ extreme impact (the project would not be sustainable).

In the first round, 29 experts gave the answers, whereas 4 experts did not respond to the given questionnaire and, therefore, ceased to be part of the expert team. Based on the aforementioned, the final expert team of the Delphi method consisted of: 14 civil engineers, 5 technology engineers, 3 spatial planners, 2 chemists, 2 environmental engineers, 2 architectural engineers and one electrical engineer. After the second round of 37 proposed risks, 16 of them received a minimum score of 1, 20 of them received a minimum score of 2 , and 1 of them received a minimum score of 3 . Two out of 37 proposed risks received a maximum score of 4 and 35 of them received a maximum score of 5 . Although $43 \%$ of the risks received a minimum score by one expert, none of these elements received a minimum score by more than 3 experts.

Table 1 Criteria for selection of experts

\begin{tabular}{|c|c|}
\hline Criterion & Explanation \\
\hline Author's work & $\begin{array}{l}\text { The expert has at least five published } \\
\text { professional and scientific papers in the field } \\
\text { of risk management or wastewater treatment }\end{array}$ \\
\hline Conference & $\begin{array}{l}\text { The expert participated in at least one } \\
\text { conference or scientific meeting in the field of } \\
\text { risk management or wastewater treatment }\end{array}$ \\
\hline $\begin{array}{l}\text { Experience in the } \\
\text { field of spatial } \\
\text { planning }\end{array}$ & $\begin{array}{l}\text { The expert participated in the development of } \\
\text { two or more spatial or town planning projects } \\
\text { in which the location of the wastewater } \\
\text { treatment plant is defined }\end{array}$ \\
\hline $\begin{array}{l}\text { Experience in the } \\
\text { field }\end{array}$ & $\begin{array}{l}\text { The expert participated in the preparation of } \\
\text { two or more previous feasibility studies or } \\
\text { feasibility studies for the construction of a } \\
\text { wastewater treatment plant }\end{array}$ \\
\hline Work experience & $\begin{array}{l}\text { The expert has five or more years of } \\
\text { experience in planning, designing or } \\
\text { constructing a wastewater treatment plant }\end{array}$ \\
\hline Faculty experience & $\begin{array}{l}\text { The expert has been employed at the faculty } \\
\text { for more than ten years }\end{array}$ \\
\hline $\begin{array}{l}\text { Professional } \\
\text { associations }\end{array}$ & $\begin{array}{l}\text { The expert has a membership in professional } \\
\text { associations (e.g. the Association of Engineers } \\
\text { and Technicians, the Chamber of Engineers, } \\
\text { the Association of Consulting Engineers) }\end{array}$ \\
\hline Licence & $\begin{array}{l}\text { The expert has a professional registration, } \\
\text { i.e. a licence (chief designer, chief contractor, } \\
\text { chief urban planner or planner) }\end{array}$ \\
\hline
\end{tabular}


In order to determine the credibility of the research and which risks should remain in the research, it is important to know how many scores higher than 2 each risk received. A score greater than 2 implies a moderate and greater impact on the project. Between $72 \%$ and $97 \%$ of the experts gave a score higher than 3 for each risk, which represents a moderate impact on the project.

Among the 37 risks, the minimum mean score for the proposed risks is 3.07, whereas the maximum is 4.14 . It can be seen that all the risks are declared as risks with moderate and greater impact on the project. This is an interesting fact because the range of the scores is small and based on this, it can be concluded that the experts believed the proposed risks had a medium or greater impact on the project. The risk rated as 3.07 is the risk from the legal risk group: "Inadequate assessment of the impact of public procurement on the course of the project and deadlines". The risk with a score of 4.14 belongs to the group of the design risks: "Lack of data on the amount of wastewater". In order to form a risk assessment model, it is necessary for experts to reach a consensus during the Delphi method.

The researcher is in charge of the consensus, as well as the active monitoring and management of the research. There is no universal viewpoint or formula about the consensus itself in the Delphi method, which is why it is necessary to rely on the previous research based on the Delphi method and conclusions from such research. It is considered that the Delphi method should be implemented through two or three rounds and that the experts should reach an agreement of $80 \%$, so that it may be said that they have reached a consensus, i.e. an agreement in opinions [28]. In the second round, the experts received a table with all the risks and their data from the second round: the mean, the median, the range of scores for a given risk, the mode or score with the highest frequency and the number of experts who had rated the risk with a score higher than 2 . The first parameter in the second round was observing the mean values of each risk assessment and comparing them to the mean values from the second round. The experts were then asked to provide their opinion whether the risk should be included in the risk assessment model, and if they agreed, to rate it, again on the basis of the Likert scale. They had the choice either to keep the same score as the mean value in the first round if they agreed with the experts' scores, or to give a new score in the same way as in the first round of the research if they believed the mean value was not a realistic measure of risk. The next parameter that was observed was the percentage of compliance of the experts, i.e. reaching a consensus reflected in how many experts had expressed their opinion about a particular risk to remain in the risk assessment model. The percentage for the consensus was determined according to the literature.

In [29], there is a list of different statistical measures used to analyze the data which include: the median, the mean, the mode, the percentage for each event, ranks, the upper and lower quartile range, regression weights (or) induced (if any) rules as well as the statistical average of the points for each factor. Additionally, in [30] it is concluded that the mean, the measure of the central tendency, can be understood to represent the opinion of the group. They suggested that the standard deviation (SD) could then be understood as a representation of the amount of disagreement within the panel. If the SD is low, the panel is in agreement. The opposite is also true: if the SD is high, the panel is in disagreement.

In order to see whether the consensus was reached after the end of the second round, new statistical data processing was performed and it was concluded that eight risks had received lower scores comparing to the last round, i.e. that the mean value was lower in the second round. A coefficient of variation was used to measure the consensus reached [31]. The coefficient of variation for a given datum during 2 iterations is the measure of the standard deviation of the response comparing to the mean [22]. Standard deviation is calculated for each datum in the research, and in this case, there were 37 standard deviations and 37 coefficients of variation. The coefficient of variation is calculated as [22] Eq. (1):

$C V=($ standard deviation $) /($ mean $)$.

A high value of the coefficient of variation (greater than 1) suggests that the experts' answers are scattered in relation to the mean value, which implies that there is a big difference in the experts' opinion in relation to the mean value. In contrast, when the value of the coefficient of variation is small, then there is also a small scatter around the mean value. To measure the stability of the response for a risk, the absolute difference in deviations for each risk is calculated Eq. (2). If there are two rounds of answers then the procedure is as follows:

$$
\Delta C V=C V_{2 \text { nd round }}-C V_{1 \text { st round }} \text {. }
$$

A small value and a value close to 0 of the absolute difference of the coefficients of variation implies the stability of the response and the achievement of consensus among the experts. Then there is no need for further rounds of the research [22]. 
In [31], it is stated that various studies are used in the Delphi research where the coefficient of variation is a measure of consensus since it allows direct comparison of the statements in certain rounds of the research. It is also defined that it is ideal when the coefficient of variation decreases in elements on a round-to-round basis. The instruction for the coefficient of variation used according to [30] is as follows, $0<V<0.5$ a good level of consensus, no need for further rounds.

The research that was conducted meets the stated criteria and all the differences between the second and the first round are negative, and according to the absolute value less than 0.5 . Therefore, it was concluded that this was the last round of the research and the risk assessment model developing could commence.

\section{Results and discussion}

After the consensus was reached by the experts, the risk assessment model which contained individual risks with their own weighting coefficients was formed (Table 2).

\subsection{Quantification process}

The calculation of relative weighting coefficients was performed by applying descriptive statistics methods [32]. Each of the risks received its own weighting factor, i.e. its own weight in relation to other risks in its own risk group.

This value was assigned to it based on its scores and the scores of other risks. In order to calculate weighting coefficients, first, all risks were classified to see how many risks there were in each group and what was the individual mean value of each of the 37 risks. After that, each risk group received its specific mean value based on the mean values and the number of risks per group.

Since there were mean values for each risk group, it was possible to calculate the weight coefficient of each group. The sum of all weighting coefficients must be 100 . Therefore, the standard calculation for the standard percentage amount was used. When each risk group received its own weighting factors, based on the total number of factors, a separate weighting factor was calculated for each risk in the group.

Each weighting coefficient shows how significant one risk is comparing to another and what impact it has on the project. The higher the sum of the weighting coefficients on the project, the more vulnerable the project and the greater the potential for delays, losses and non-functionality are. The value of the coefficient is determined based on a set of questions that differ for each coefficient. Examples of the questions are presented in the appendix of this paper.

\subsection{Discussion of results}

Each of these risks presented in Table 2 can affect the project and lead to delays in the project itself and financial losses. The experts provided their scores in two rounds and reached the consensus after the second round. A weighting coefficient is determined for each risk and it shows how significant a certain risk is as well as how much it affects the project itself, and all the risks can be compared with each other.

This system for evaluating the projects of the wastewater treatment plant has been developed so that at the very beginning of the project, i.e. before the work realization process starts, the risks that a project can bring are considered in time. The more the score of the project, the greater the possibility of delays and financial losses on the project. Risk model is initially verified by experts from Delphi team, after model is made, on two projects during construction phase. In addition, the risks do not have to be observed separately, but the risk group itself has its own weight coefficient (the number obtained by adding all the weight coefficients in the group). The goal of each project is to collect fewer than 50 points when the characteristic risks of that project are added up.

It is also important to look at the weighting coefficients themselves and certain risk groups. It is clear that the risks in the group of logistics risks and environmental risks are with a very high weighting factor, which can be easily explained from an engineering point of view. The impact of the wastewater treatment plant on human health and the ecosystem is one of the most important points when considering the location of the plant itself. If there is an error in this field, the consequences can be great. Additionally, in logistics risks, there can be major issues about the location of the plant and the dimensions of the facilities, as well as the choice of the treatment techniques due to the lack of communication with public utility companies and a sufficient number of engineers who have many years of experience in designing plants. Other risk groups are equal to the total weighting factor, but the group of design risks is still in the lead. This is a logical sequence of events and it can be seen that the experts were in agreement, because after the wrong location of the plant, the biggest role belongs to the design solutions, i.e. the coordination and knowledge of the team that designs the plant. 
Table 2 Research results using the Delphi method and weighting coefficients

\begin{tabular}{|c|c|c|c|}
\hline Risk name & $\begin{array}{l}\text { Difference between the mean } \\
\text { values of the significance } \\
\text { coefficient in the second and } \\
\text { the first round } \\
\left(\Delta \bar{\chi}=\bar{\chi}_{2 \text { nd round }}-\bar{\chi}_{1 \text { st round }}\right)\end{array}$ & $\begin{array}{l}\text { Difference between the } \\
\text { coefficients of variation } \\
\text { in the second and the first } \\
\text { round } \\
\Delta C V=C V_{2 \text {.round }}-C V_{1 \text {.round }}\end{array}$ & $\begin{array}{c}\text { Final value } \\
\text { of the } \\
\text { significance } \\
\text { coefficient }\end{array}$ \\
\hline \multicolumn{4}{|l|}{ LEGAL RISKS } \\
\hline 1.1 Frequent changes and modifications of laws and by-laws $[33,22]$ & -0.08 & -0.10 & 1.1 \\
\hline $\begin{array}{l}\text { 1.2. Incompatibility between regulations of the foreign investor and } \\
\text { regulations of the country where the work is to be done [34] }\end{array}$ & -0.09 & -0.05 & 1.2 \\
\hline 1.3. Ignorance of the existing laws and by-laws [33] & 0.10 & -0.12 & 1.3 \\
\hline $\begin{array}{l}\text { 1.4. Delay in resolving a contractual dispute between the investor } \\
\text { and the designers in the design phase [33] }\end{array}$ & -0.01 & -0.04 & 1.1 \\
\hline $\begin{array}{l}\text { 1.5. Untimely issued terms and licences for designing by the public } \\
\text { company [34] }\end{array}$ & 0.20 & -0.07 & 1.2 \\
\hline $\begin{array}{l}\text { 1.6. Inadequate terms for connecting wastewater treatment plant into } \\
\text { infrastructure [14] }\end{array}$ & -0.11 & -0.10 & 1.2 \\
\hline $\begin{array}{l}\text { 1.7. Inadequate estimation of public procurement impact on the life } \\
\text { cycle and deadline of the project [7] }\end{array}$ & 0.05 & -0.05 & 1.1 \\
\hline 1.8. Inadequate criteria for selection of the project dealer [34] & -0.02 & -0.08 & 1.3 \\
\hline 1.9. Inadequate criteria for selection of the project designer [34] & 0.25 & -0.06 & 1.4 \\
\hline 1.10. Inadequate criteria for selection of the contractor [34] & 0.10 & -0.06 & 1.4 \\
\hline $\begin{array}{l}\text { 1.11. Inadequate view of the optimal way of the project realization } \\
\text { contracting [33] }\end{array}$ & 0.03 & -0.09 & 1.2 \\
\hline $\begin{array}{l}\text { 1.12. Inadequate spatial plan of the municipality (location, dimension } \\
\text { and size) (based on interviews with experts and experience of authors) }\end{array}$ & 0.03 & -0.07 & 1.4 \\
\hline 1.13. Issues with getting the building permit $[33,34]$ & -0.27 & -0.04 & 1.1 \\
\hline \multicolumn{4}{|l|}{ FINANCIAL AND ECONOMIC RISKS } \\
\hline 2.1. Inadequate budget (lack of funds) for building modern plants [14] & 0.11 & -0.01 & 3.7 \\
\hline 2.2. Uncontrolled cash flow in some phases of the project $[22,33]$ & 0.10 & -0.05 & 3.3 \\
\hline 2.3. Inflation and unexpected price change $[22,33]$ & -0.13 & -0.08 & 3.0 \\
\hline 2.4. Unfinished and incorrect estimation of financial benefits [5] & 0.03 & -0.06 & 3.1 \\
\hline 2.5. Unfinished and incorrect estimation of economic benefits [5] & 0.03 & -0.03 & 3.0 \\
\hline \multicolumn{4}{|l|}{ LOGISTICS RISKS } \\
\hline $\begin{array}{l}\text { 3.1. Lack of communication with public companies (changes in the } \\
\text { primary parameters of designing) }[22,34]\end{array}$ & 0.01 & 0.02 & 8.2 \\
\hline 3.2. Lack of qualified designers of wastewater treatment plants [34] & 0.25 & -0.01 & 8.9 \\
\hline \multicolumn{4}{|l|}{ ECOLOGICAL RISKS } \\
\hline $\begin{array}{l}\text { 4.1. The location of the plant is not adequate in terms of } \\
\text { environmental protection (ecosystem disturbance) [5] }\end{array}$ & 0.19 & -0.06 & 9.2 \\
\hline $\begin{array}{l}\text { 4.2. The location of the plant is not adequate in terms of distance and } \\
\text { position from a populated place [5] }\end{array}$ & 0.19 & -0.10 & 9.1 \\
\hline \multicolumn{4}{|l|}{ MANAGEMENT RISKS (PROJECT MANAGEMENT) } \\
\hline $\begin{array}{l}\text { 5.1. Lack of qualified staff working in public companies (based on } \\
\text { interviews with experts and experience of authors) }\end{array}$ & 0.10 & -0.01 & 2.4 \\
\hline $\begin{array}{l}\text { 5.2. Bad communication between the participants (designers) on the } \\
\text { project [34] }\end{array}$ & 0.31 & -0.02 & 2.4 \\
\hline $\begin{array}{l}\text { 5.3. Insufficient professionalism of the investor in the design phase in } \\
\text { terms of providing information for the designer [34] }\end{array}$ & -0.03 & -0.10 & 2.1 \\
\hline 5.4. Slow investor decisions that slow down the designing process [33] & 0.05 & -0.05 & 2.1 \\
\hline 5.5. Inadequate structure of the team for realization of the investment [5] & 0.29 & -0.05 & 2.4 \\
\hline 5.6. Missing the project leader by the investor [5] & 0.16 & -0.13 & 2.4 \\
\hline 5.7. Unrealistic project deadline planning by the investor [33] & 0.42 & -0.12 & 2.5 \\
\hline
\end{tabular}




\begin{tabular}{|c|c|c|c|}
\hline Risk name & $\begin{array}{l}\text { Difference between the mean } \\
\text { values of the significance } \\
\text { coefficient in the second and } \\
\text { the first round } \\
\left(\Delta \bar{\chi}=\bar{\chi}_{2 \text { nd round }}-\bar{\chi}_{1 \text { st round }}\right)\end{array}$ & $\begin{array}{l}\text { Difference between the } \\
\text { coefficients of variation } \\
\text { in the second and the first } \\
\text { round } \\
\Delta C V=C V_{2 \text {.round }}-C V_{1 \text {.round }}\end{array}$ & $\begin{array}{l}\text { Final value } \\
\text { of the } \\
\text { significance } \\
\text { coefficient }\end{array}$ \\
\hline \multicolumn{4}{|l|}{ DESIGN RISKS } \\
\hline 6.1. Lack of data on the amount of wastewater $[33,34]$ & -0.15 & -0.03 & 2.2 \\
\hline 6.2. Lack of data for the recipient (water quality, flow, water level) [34] & 0.08 & -0.11 & 2.0 \\
\hline 6.3. Inadequate demographic assessment $[22,34]$ & 0.44 & -0.19 & 2.2 \\
\hline 6.4. Insufficient data for the existing sewer system $[22,34]$ & 0.13 & -0.10 & 2.0 \\
\hline 6.5. Uncoordinated work between different types of designers $[22,34]$ & 0.22 & -0.09 & 2.0 \\
\hline 6.6. Unknown planned/ desired equipment by the designer $[22,34]$ & 0.19 & -0.06 & 2.1 \\
\hline $\begin{array}{l}\text { 6.7. Excessive distance of municipalities which must be connected to } \\
\text { the plant [22] }\end{array}$ & 0.05 & -0.16 & 1.8 \\
\hline 6.8. Changing of wastewater treatment technology $[22,34]$ & 0.29 & -0.10 & 2.1 \\
\hline
\end{tabular}

\section{Conclusions}

This research discusses risk structure which incorporates legal, financial and economic, logistics, ecological, management and design risks, which are not connected to technological aspects and technology of wastewater treatment. These risks are connected to the risks in the creation and design phase of the project. All risks presented are rated by the experts, the participants in the Delphi method. After two rounds, the respondents reached a consensus, which was confirmed by the methods of descriptive statistics. Weighting coefficients were found for each risk and they represent the impact on the wastewater treatment plant project. The main significance of the presented model is a better understanding of risk factors which can lead to the reduction in financial losses and better sustainability of the project.

The limitations of the research are small number of experts with managerial experience in the Delphi team and

\section{References}

[1] Tchobanoglous, G., Burton, F. L., Stensel, H. D. "Wastewater Engineering, Treatment and Reuse", 4th ed., McGraw-Hill Education, New York, NY, USA, 2003.

[2] Milutinović, R. "Doctrine - Accept Waste Water, Purify and Use It (APU) (Abstract)", Danubius, 2013. [online] Available at: http:// danube-cooperation.com/danubius/2013/12/24/doctrine-acceptwaste-water-purify-use-apu-abstract/

[3] Ministry of Environmental Protection of Serbia "Treatment of communal wastewater, technological view and critical view of actual objects, giving the optimal proposal for wastewater treatment plants, with aspects for protection of water, air and land of settlements in Serbia", Ministry of Environmental Protection of Serbia, Belgrade, Serbia, 1999. (in Serbian)

[4] Riffat, R. "Fundamentals of Wastewater Treatment and Engineering", CRC Press, Boca Raton, FL, USA, 2012. the fact that experts participating in this research were from only two countries, Serbia and Bosnia and Herzegovina.

Further focus of this research is on the application of the model on the implemented projects of the plants or the projects of the planned plants, which will enable the analysis of the accuracy of the model and its additional calibration. Furthermore, it is planned to expand the research to the other countries in the Western Balkan in order to improve the model. Such results can greatly facilitate the decision-making and planning processes of future wastewater treatment plant projects.

\section{Acknowledgement}

This research has been supported by the Ministry of Education, Science and Technological Development through the project no. 451-03-68/2020-14/200156: "Innovative scientific and artistic research from the FTS domain".

[5] Walewski, J. A., Gibson, Jr., G. E., Vines, E. F. "Risk identification and assessment for international construction projects", [pdf] In: Global project management handbook, 2nd ed., McGraw-Hill, New York, NY, USA, 2006. Available at: http://www.icoste.org/ Slovenia2006Papers/icecFinal00033.pdf

[6] Renault, B. Y., Agumba, J. N. "Risk management in the construction industry: a new literature review", MATEC Web of Conferences 66, Article number: 00008, 2016.

https://doi.org/10.1051/matecconf/20166600008

[7] Ogunsanmi, O. E., Salako, O. A., Ajaui, O. M. "Risk Classification Model for Design and Build Projects", Journal of Engineering, Project, and Production Management, 1(1), pp. 46-60, 2011. http://doi.org/10.32738/JEPPM.201107.0006

[8] Belia, E., Neumann, M. B., Benedetti, L., Johnson, B., Murthy, S., Weijers, S., Vanrolleghem, P. A. "Uncertainty in Wastewater Treatment Design and Operation", [e-book] IWA Publishing, London, UK, Rep. 21, 2020. 
[9] Van der Merwe-Botha, M., Manus, L. "Wastewater Risk Abatement Plan, W2RAP Template", [pdf] Water Research Comission, Pretoria, South Africa, 2011. Available at: http://www.wrc.org.za/wp-content/uploads/mdocs/TT\%20624.pdf

[10] Van der Merwe-Botha, M., Manus, L. "Wastewater Risk Abatement Plan A W2RAP GUIDELINE To plan and manage towards safe and complying municipal wastewater collection and treatment in South Africa", [pdf] Water Group Holdings (Pty) Ltd, Department of Water Affairs, Pretoria, South Africa, Rep. TT 489/11, 2011. Available at: http://www.wrc.org.za/wp-content/uploads/mdocs/ TT\%20489-11.pdf

[11] Belia, E., Johnson. B. "Uncertainty Evaluations in Model-Based WRRF Design for High Level Nutrient Removal", [pdf] Water Environment Research Foundation, Alexandria, VA, USA, Rep. NUTR1R06q, 2013. Available at: https://modeleau.fsg.ulaval.ca/ fileadmin/modeleau/documents/Publications/pvr1116.pdf

[12] Grady, Jr., C. P. L., Daigger, G. T., Love, N. G., Filipe, C. D. M. "Biological Wastewater Treatment", 3rd ed., IWA Publishing, London, UK, 2011.

[13] Bowers, D. "Risk Management: Past, Present and Future Directions", Nova Science Publisher, New York, NY, USA, 2016,

[14] CEDEF "Use and treatment of municipal and industrial wastewater in the Republic of Serbia", [pdf] CEDEF and the Provincial Secretariat for Urbanism, Construction and Environmental Protection, Novi Sad, Serbia, 2015. Available at: https://drive.google.com/file/d/0B5otVVm41sb5S2tSVERFOERON3c/view (in Serbian)

[15] Jaroslav Črni Institute for the Development of Water Resources "Strategy of Water Management in the Republic of Serbia", [pdf] Jaroslav Černi Institute for the Development of Water Resources, Belgrade, Serbia, 2015. Available at: http://www.rdvode.gov.rs/doc/ Strategija\%20upravljanja\%20vodama.pdf (in Serbian)

[16] Environmental Protection Agency "Report on the state of the environment in the Republic of Serbia for 2018", [pdf] Environmental Protection Agency, Belgrade, Serbia, 2019. (in Serbian) Available at: http://www.sepa.gov.rs/download/Izvestaj2018.pdf

[17] German ATV Rules and Standards "ATV - A 106E Design and Construction Planning of Wastewater Treatment Facilities", GFA, Hennef, Germany, 1995. [online] Available at: http://l.mozh.org/ up/ATV-A_106E.pdf

[18] Cerić, A., Marić, T. "Determination of Priority during the Management of the Project", Građevinar, 63(3), pp. 265-271, 2011. (in Croatian)

[19] Mirabi, M., Mianabadi, H., Zarghami, M., Bagher Sharifi, M., Mostert, E. "Risk-based evaluation of wastewater treatment projects: A case study in Niasar city, Iran", Resources, Conservation and Recycling, 93, pp. 168-177, 2014.

https://doi.org/10.1016/j.resconrec.2014.10.002

[20] Boznak, R. G. "On the horizon - a 24-month car, the question is, who will achieve it?", Project Management Journal, 22(3), pp. 11-16, 1991. [online] Available at: https://www.pmi.org/learning/ library/24-month-car-development-competition-success-2086

[21] Mikić, M. S. "Risk Management during planning and construction of large infrastructure projects for improving their sustainability", [pdf] PhD Thesis, University of Belgrade, 2015. (in Serbian) Available at: https://nardus.mpn.gov.rs/handle/123456789/4184
[22] Kishan, P., Bhatt, R., Bhavsar, J. J. "A Study of Risk Factors Affecting Building Construction Projects", International Journal of Engineering, Research \& Technology, 3(12), pp. 831-835, 2014, [online] Available at: https://www.ijert.org/a-study-of-risk-factorsaffecting-building-construction-projects

[23] Linstone, H. A., Turoff, M. "The Delphi Method: Techniques and Applications", Journal of Marketing Research, 13(3), pp. 317-318, 1976.

[24] Gordon, T. J. "The Delphi Method", [pdf] The Millennium Project, Washington, DC, USA, 2009. Available at: http://www.millennium-project.org/wp-content/uploads/2020/02/04-Delphi.pdf

[25] Creswell, J. W. "Planning, conducting and evaluating quantitative and qualitative research", 4th ed., Pearson, Boston, MA, USA, 2012,

[26] Ameyaw, E. E., Hu, Y., Shan, M., Chan, A., P., C., Le, Y. "Application of Delphi method in construction engineering and management research: a quantitative perspective", Journal of Civil Engineering and Management, 22(8), pp. 991-1000, 2016. https://doi.org/10.3846/13923730.2014.945953

[27] Kaminsky, J., Javernick-Will, A. "Contested Factors for Sustainability: Construction and Management of Household On-Site Wastewater Treatment Systems", Journal of Construction Engineering and Management, 139(12), 2013. https://doi.org/10.1061/(ASCE)CO.1943-7862.0000757

[28] Greatorex, J., Dexter, T. "An accessible analytical approach for investigating what happens between the rounds of a Delphi study", Journal of Advanced Nursing, 32(4), pp. 1016-1024, 2000. https://doi.org/10.1046/j.1365-2648.2000.t01-1-01569.x

[29] Rowe, G., Wright, G. "The Delphi Technique: Past, present and future prospects - Introduction to the special issue", Technological Forecasting and Social Change, 78(9), pp. 1487-1490, 2011. https://doi.org/10.1016/j.techfore.2011.09.002

[30] von der Gracht, H. A. "Consensus measurement in Delphi studies: Review and implications for future quality assurance", Technological Forecasting and Social Change, 79(8), pp. 1525-1536, 2012. https://doi.org/10.1016/j.techfore.2012.04.013

[31] Yang, Y. N. "Convergence on the Guidelines for Designing a Web-Based Art-Teacher Education Curriculum: A Delphi Study", [pdf] presented at Annual meeting of the American Educational Research Association, New Orleans, LA, USA, April, 24-28, 2000. Available at: https://files.eric.ed.gov/fulltext/ED446747.pdf

[32] Velkovski, T. "Reference Rating Model for the Level of Implementation of the Occupational Safety and Health Systems", [pdf] PhD Thesis, Ss. Cyril and Methodius University in Skopje, 2019. (in Macedonian) Available at: https:/www.mf.ukim.edu.mk/ sites/default/files/Doktorat\%20Trajce\%20Velkovski\%20web.pdf

[33] Wideman, R. M. (ed.) "Project and Program Risk Management: A guide to managing project risks and opportunities", Project Management Institute, Newtown Square, PA, USA, 1992.

[34] Aziz, R. F. "Ranking of delay factors in construction projects after Egyptian revolution", Alexandria Engineering Journal 52(3), pp. 387-406, 2013.

https://doi.org/10.1016/j.aej.2013.03.002 


\section{Appendix}

Table 3 A Rating System Example of the Credit Allocation Methodology

\begin{tabular}{|c|c|}
\hline 4.1. The location of the plant is not adequate in terms of environmental protection (ecosystem disturbance) & $\begin{array}{l}\text { Credits }(C) \\
C_{\max }=9.20\end{array}$ \\
\hline \multirow{2}{*}{ 1. Can the location of the WWTP affect the ecosystem and the environment? } & Yes - 1 point \\
\hline & No - 0 points \\
\hline \multirow{2}{*}{ 2. Has an environmental impact assessment study been done for the WWTP? } & Yes - 0 points \\
\hline & No - 1 point \\
\hline Points scored & $X$ \\
\hline Maximum points that can be scored & 2 \\
\hline Realization percentage \% & $P=X / 2 * 100 \%$ \\
\hline Total credits scored & $C=P * 9.20$ \\
\hline
\end{tabular}

